\title{
Efeito retroativo do vestibular da Universidade Federal do Paraná no ensino de língua inglesa em nível médio no Paraná
}

uma investigação em escolas públicas, particulares e cursos pré-vestibulares

$2^{\mathrm{a}}$ edição 

MIRIAM SESTER RETORTA

\section{Efeito retroativo do vestibular}

da Universidade Federal do Paraná no ensino de língua inglesa em nível médio no Paraná

uma investigação em escolas públicas, particulares e cursos pré-vestibulares 
Efeito retroativo do vestibular da Universidade Federal do Paraná no ensino de língua inglesa em nível médio no Paraná: uma investigação em escolas públicas, particulares e cursos pré-vestibulares

(C) 2017 Miriam Sester Retorta

Editora Edgard Blücher Ltda.

$1^{\mathrm{a}}$ edição - 2010

$2^{a}$ edição - 2017

\section{Blucher}

Rua Pedroso Alvarenga, 1245, $4^{\circ}$ andar 04531-934 - São Paulo - SP - Brasil Tel.: $55113078-5366$ contato@blucher.com.br www.blucher.com.br

Segundo o Novo Acordo Ortográfico, conforme 5. ed. do Vocabulário Ortográfico da Língua Portuguesa, Academia Brasileira de Letras, março de 2009.

É proibida a reprodução total ou parcial por quaisquer meios sem autorização escrita da editora.

Todos os direitos reservados pela Editora Edgard Blücher Ltda.
Dados Internacionais de Catalogação na Publicação (CIP) Angélica Ilacqua CRB-8/7057

Retorta, Miriam Sester

Efeito retroativo do vestibular da Universidade Federal do Paraná no ensino de língua inglesa em nível médio no Paraná : uma investigação em escolas públicas, particulares e cursos pré-vestibulares [livro eletrônico] / Miriam Sester Retorta. - 2. ed. - São Paulo : Blucher, 2016. 466 p. : PDF ; il.

Bibliografia ISBN 978-85-8039-154-1 (e-book)

1. Universidades e faculdades Vestibular - Brasil 2. Língua inglesa Avaliações I. Título.

16-0342

CDD 378.16640981

Índices para catálogo sistemático:

1. Universidades e faculdades Vestibular - Brasil 
Para o aluno/candidato anônimo da Unesp de 2005. 



\section{Agradecimentos}

Foram muitos os que me ajudaram a concluir este trabalho.

Meus sinceros agradecimentos

A Matilde, minha orientadora, apaixonada por idéias; capaz de transformar sonhos em realidade, ainda que, muitas vezes, precise passar por muitos obstáculos; perseverante, ousada; surpreendente, sempre; mulher paciente, dedicada, eficiente; pesquisadora competente, que me ajudou e me incentivou em momentos difíceis; mostrou-me o que é seriedade; uma eterna amiga.

Às Professoras Joanne Busnardo e Rosa Maria Nery, pelas sugestões feitas por ocasião das qualificações;

Aos professores Ângela Kleiman e Jomar A. Camarinha Filho, pela ajuda e pela orientação das qualificações em língua materna e estatística;

À minha mãe e ao meu pai, meus eternos incentivadores e grandes amigos nesta vida;

Ao José, alma gêmea, amigo, amante, conselheiro, analista, cúmplice, revisor de texto, financiador desta empreitada, meu eterno amor;

Aos meus queridos filhos Fábio e André, por me fazerem lembrar que existem outras coisas importantes, além deste trabalho;

À Mirian e todas as crianças e amigos da "Casa do Pai", por me mostrarem que podemos escrever uma nova história de vida;

À minha querida irmã Ivete, que me ajudou a revisar meu trabalho diversas vezes, além de me incentivar em momentos de desânimo;

À minha irmã Rita e ao meu sobrinho-poeta Eros, pela luta por conhecimento, apesar das diversidades que enfrentamos na vida;

Às minhas primas Elizete e Ana Paula, pelas palavras de incentivo; 
Aos colegas do "Centro de Línguas da Universidade Tecnológica Federal do Paraná", pela sobrecarga causada pelos cursos que deixei de dar;

Às coordenadoras do Calem, Eliane Oliveira e Márcia Lopes, pelo apoio que me deram durante os últimos cinco anos;

À Cecília de Almeida, minha colega de doutorado, e a seu marido Ismar, por estarem por perto e me ajudarem muito quando o pânico tomava conta;

À Thais Marochi, pelo apoio e pelas sugestões sobre os exames da UFPR;

Ao Professor José Erasmo Gruginski, pela sua ajuda e pelo apoio durante a coleta de dados da pesquisa;

Às queridas amigas professoras de francês Estela de A. Bastos, Carla Portella, Marilene Garcias, Noemi H Perdigão, Fernanda Lisboa, Eveline Mizuguchi, que tanto me ajudaram na difícil missão de aprender uma língua estrangeira;

À aluna Luciana de Azevedo, que me ensinou que o fracasso e a derrota passam e que a vitória, após uma difícil batalha, é muito mais prazerosa;

A todos os sujeitos desta pesquisa, pela paciência e cooperação durante a exaustiva coleta de dados. 


\section{Resumo}

Este trabalho visa investigar se a prova de língua inglesa do vestibular da Universidade Federal do Paraná causa efeitos retroativos no ensino dessa língua, em escolas públicas e privadas de nível médio e cursos pré-vestibulares, e, em caso positivo, determinar quais são esses efeitos. Para atingir tais objetivos, foi desenvolvida uma pesquisa qualitativa interpretativista de cunho etnográfico, na qual puderam ser ouvidas diversas vozes da comunidade escolar: escolas públicas (urbanas e rurais) e particulares, bem como cursos pré-vestibulares (particulares e gratuitos). Na busca de multiperspectivas sobre o fenômeno, procurou-se escolher os cenários que levassem em conta a grande desigualdade social do país, e incluíssem, como participantes, a maioria dos stakeholders (pessoas ligadas ao fenômeno direta ou indiretamente) para, ao final, triangularem-se os dados coletados. Além de entrevistas dos participantes, aulas de professores também foram observadas. Os resultados deste estudo mostram que o efeito retroativo da prova de inglês do vestibular da UFPR não ocorre nas escolas públicas. O que direciona o ensino desses cenários são os livros didáticos que cada escola adota. No entanto, pudemos perceber a existência do efeito retroativo nos outros cenários - escolas particulares e cursos pré-vestibulares -, ora exercendo efeitos positivos (motivação dos diretores e professores para buscar informações sobre o exame; motivação dos alunos para estudar mais a disciplina e passar no exame; direcionamento de ementas e construção de objetivos claros; incentivo ao ensino da leitura), ora negativos (estreitamento do currículo; ansiedade dos sujeitos dos cenários). Verificou-se também que o efeito retroativo ocorreu aí em intensidades diferentes, pois interferiram no fenômeno fatores como: informações que os professores tinham sobre o exame; concepções de língua, leitura e avaliação desses professores; nível de conhecimento de língua inglesa desses profissionais; cobrança dos diretores e do 
grupo social (os pais e alunos); chances de aprovação, dentre outros. O que direcionou o ensino desses cenários foi o programa oficial do exame de vestibular da UFPR. Este estudo oferece contribuições teóricas ao proporcionar melhor entendimento do conceito efeito retroativo; contribuições metodológicas, por seu desenho investigativo inovador e abrangente; e, finalmente, contribuições práticas, enquanto um conjunto de subsídios para o ensino e avaliação de língua inglesa no ensino médio. 


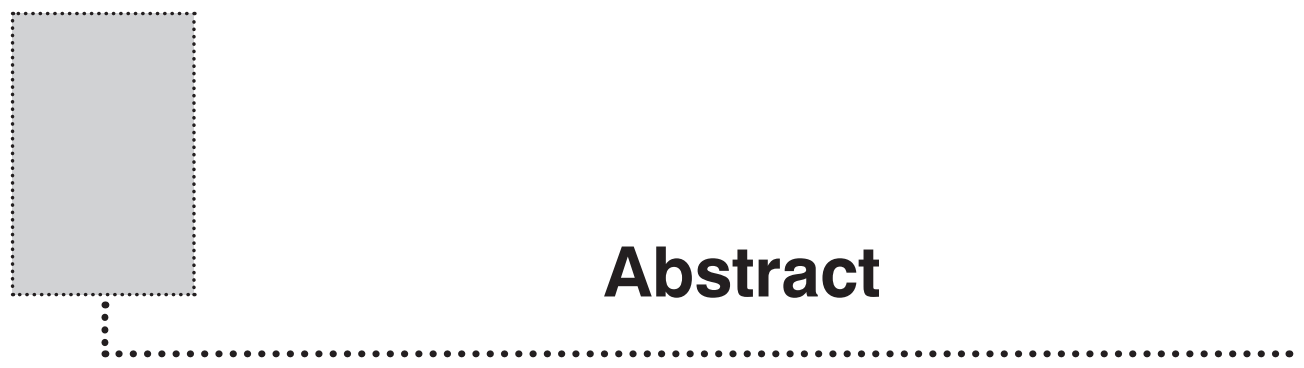

The objective of this thesis is to investigate if the English test of the University Entrance Examination of UFPR sets off the washback effect in the teaching/learning of the language in public and private high schools as well as cramming courses and, if so, what effects were they. In order to meet these objectives a qualitative interpretativist investigation was conducted in which various voices of the school community were heard such as the participants of public schools (urban and rural), the private schools and the cramming courses (private and free ones). Since there was an intention of having a multiperspective of the phenomenon, the scenarios were chosen because of the great social inequalities of this country and, therefore, many stakeholders (participants who were directly or indirectly involved in the phenomenon) were selected to be interviewed. The data was triangulated, analyzed and discussed. Besides the interview, class observations were included. The results of this study show that there was no washback effect of the English test of the University Entrance Examination of UFPR in public schools. What helped set the teaching goals of the discipline were the contents suggested in the didactic books adopted in each school. In the other scenarios, the washback effect was observed. The positive effects were the motivation of the directors and teachers to search for information about the test; motivation of the students to study harder to pass the test; the test was used to set clear teaching objectives and reading began to be taught. The negative effects were: anxiety of the participants of some scenarios and curriculum narrowing. Different intensities of the washback effect were observed because there were other factors which interfered in the phenomenon such as information teachers had about the test, their concept of language, reading and evaluation, their knowledge of the English language, the directors demanding for the teachers' best, the social group 
(parents and students) demanding for the teachers' best and the chances the students had in being approved, among others. The official program of the test was used to guide the teaching/learning of these scenarios. This study offers a theoretical contribution when it helps us understand a bit more about the washback effect; methodological contribution due to the research design which is innovative and broad and, finally, a practical contribution because it intends to offer a set of information which can give support to the teaching and evaluation of the English discipline in high schools. 


\section{Lista de tabelas}

Tabela 1 Renda mensal familiar dos candidatos ao vestibular da

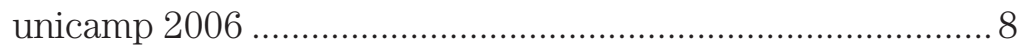

Tabela 2 Distribuição das pessoas ocupadas de 10 ou mais por classe de rendimento no trabalho principal - 2004 ............... 9

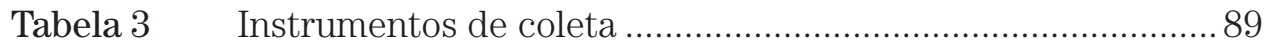

Tabela 4 Cronograma de coleta de dados ............................................ 94 



\section{Lista de quadros}

Quadro 1 Emergência da competência comunicativa .......................... 27

Quadro 2 Elaboração da competência comunicativa............................. 27

Quadro 3 Competência de linguagem.................................................. 35

Quadro 4 Alguns componentes do uso lingüístico e do desempenho de linguagem de teste ...................................... 36

Quadro 5 Estratégias metacognitivas no uso lingüístico e no

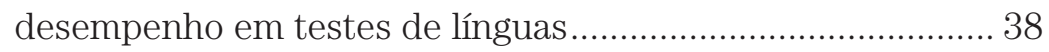

Quadro 6 Resumo de diferenças entre concepções de validade

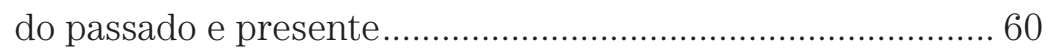

Quadro $7 \quad$ Sujeitos da pesquisa ............................................................ 104 

Figura 1 Trem na índia................................................................... 1

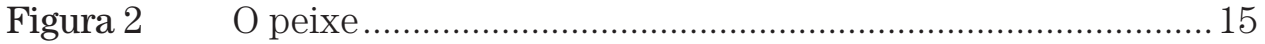

Figura 3 Esquema geral matriz de questões........................................ 47

Figura $4 \quad$ O dilema tridimensional da validade, confiabilidade

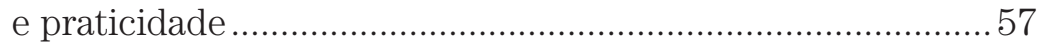

Figura 5 Um modelo básico de efeito retroativo (bailey, 1996, p. 264)....74

Figura 6 Teoria tradicional do efeito retroativo: modelo de

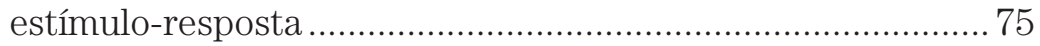

Figura 7 Efeito retroativo dos anos 90: um modelo da 'caixa preta' ....75

Figura 8 Uma proposta de efeito retroativo: um modelo de inovação

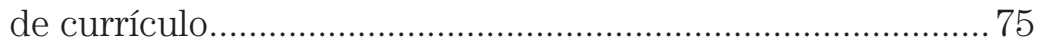

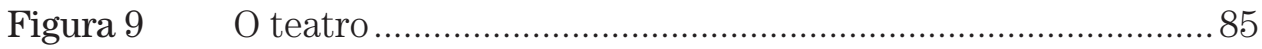

Figura $10 \quad$ O município de quitandinha................................................. 97

Figura 11 Colégio Estadual EFA - Escola pública rural........................ 98

Figura 12 Colégio Estadual LC - Escola pública urbana ....................... 99

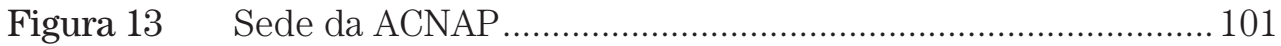

Figura 14 Aula do curso EA.............................................................. 103

Figura 15 Alunos da Escola pública rural ............................................. 108

Figura 16 Alunos da Escola pública urbana.......................................... 109

Figura 17 Alunos do Colégio DP........................................................ 110

Figura 18 Alunos do colégio DB e curso pré-vestibular......................... 110

Figura 19 Alunos do curso pré-vestibular KN ...................................... 111 
Xviii

Figura 20 Alunos do curso pré-vestibular em ação .................................. 112

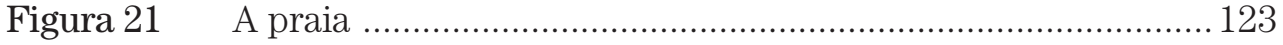

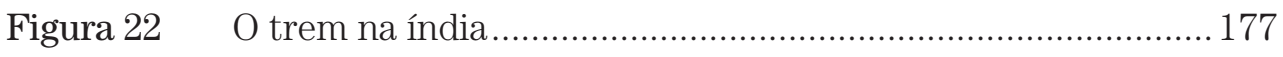

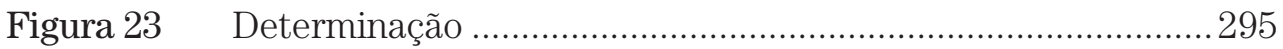

Figura 24 Efeito retroativo em escolas públicas, particulares e cursos pré-vestibulares .................................................................... 301 


\section{Lista de gráficos}

Gráfico 1 Renda da população x renda dos estudantes de

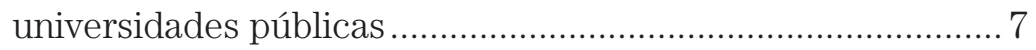





\section{Conteúdo}

\section{PRIMEIRO VOLUME}

1. Introdução .......................................................................... 3

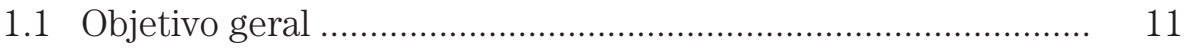

1.2 Perguntas de pesquisa ........................................................... 11

1.3 O contexto da pesquisa........................................................... 11

1.4 Organização do trabalho ............................................................ 12

2. As tendências na área de avaliação, o efeito retroativo e o

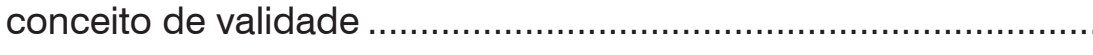

2.1 Concepções de linguagem, abordagens de ensino e de avaliação em língua estrangeira: uma restrospectiva histórica................ 18

2.1.1 Avaliação anterior aos anos 40: o período pré-científico ou The Garden of Eden (O Jardim do Éden)........... 19

2.1.2 Avaliação dos anos 40 aos 60: o período do psicométrico-estruturalista ou The Vale of Tears (O Vale de Lágrimas)

2.1.3 Avaliação nos anos 70: o período psicolingüístico-sociolingüístico ou The Promised Land (A Terra Prometida) ................ 26

2.1.4 Avaliação no final do século XX .................................... 31

2.1.5 Avaliação no novo século: o paradigma comunicativo... 32 2.1.5.1 Evolução das avaliações no paradigma comunicativo.

2.2 Os modelos/visões de leitura ...................................................... 43

2.2.1 Uma matriz de questões............................................... 45 
2.3 O conceito de validade ............................................................. 51

2.3.1 Validade de conteúdo ................................................... 51

2.3.2 Validade de construto .................................................. 52

2.3.3 Validade referenciada em critério ................................. 53

2.3.4 Validade de face......................................................... 54

2.3.5 O conceito de confiabilidade......................................... 54

2.3.6 Praticidade ................................................................ 55

2.3.7 O dilema da validade, confiabilidade e praticidade ....... 56

2.3.8 Esquema de validação de Messick................................ 58

2.4 Efeito retroativo .................................................................. 61

2.4.1 Efeito retroativo: positivo, negativo, ambos ou nenhum? .... 62

2.4.1.1 Efeito retroativo positivo …........................... 63

2.4.1.2 Efeito retroativo negativo .............................. 68

2.4.1.3 Dimensões do efeito retroativo....................... 68

2.4.2 Estudos sobre efeito retroativo: breve panorama

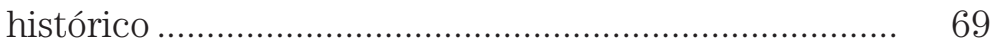

2.4.3 Metodologia das pesquisas sobre efeito retroativo........ 76

2.4.4 Estudos sobre o efeito retroativo no Brasil................... 77

3. O desenho e a metodologia de pesquisa.................................. 87

3.1 O desenho de pesquisa: a escolha da metodologia................... 87

3.2 Procedimentos e instrumentos de pesquisa ............................. 89

3.2.1 Observação em sala de aula ......................................... 90

3.2.2 Questionário I para os alunos das escolas observadas .. 90

3.2.3 Entrevista I para professores das escolas observadas... 91

3.2.4 Questionário II (ou entrevista II) para os diretores e/ou coordenadores das escolas observadas................. 92

3.2.5 Questionário III para elaboradores da prova de língua inglesa do vestibular da UFPR..................................... 92

3.2.6 Questionário IV (ou entrevista) para os autores dos livros e apostilas das escolas observadas ..................... $\quad 92$

3.2.7 Entrevista com a coordenadora de língua inglesa para escolas públicas da Secretaria Estadual de Educação

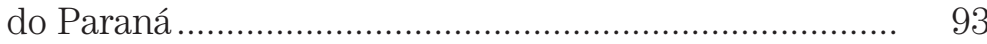

3.2.8 Análise documental .................................................... 93

3.2.9 Cronograma da coleta de dados .................................... 94

3.3 Cenários da pesquisa............................................................. 96

3.3.1 Seleção e descrição dos cenários .................................. 97 
3.3.1.1 Colégio Estadual EFA...................................... 97

3.3.1.2 Colégio Estadual LC....................................... 99

3.3.1.3 Colégio DP, escola particular ......................... 100

3.3.1.4 Colégio DB, escola particular e curso pré-vestibular............................................. 100

3.3.1.5 Curso pré-vestibular para afrodescendentes.. 101

3.3.1.6 Curso pré-vestibular EA................................. 103

3.4 Sujeitos da pesquisa ......................................................... 105

3.4.1 Os professores das escolas investigadas ..................... 105

3.4.1.1 Professora do colégio público rural............... 105

3.4.1.2 Professora do colégio público urbano ............ 106

3.4.1.3 Professora do colégio particular DP .............. 106

3.4.1.4 Professora do Colégio DB .............................. 106

3.4.1.5 Professor do curso pré-vestibular KN ............ 106

3.4.1.6 Professor do curso pré-vestibular EA ............ 107

3.4.2 Os alunos das escolas investigadas.............................. 107

3.4.2.1 Alunos da escola pública rural....................... 107

3.4.2.2 Alunos da escola pública urbana ................... 108

3.4.2.3 Alunos da escola particular - Colégio DP ....... 109

3.4.2.4 Alunos da escola particular e curso pré-vestibular - Colégio DB ........................... 110

3.4.2.5 Alunos do curso pré-vestibular KN ............... 111

3.4.2.6 Alunos do curso pré-vestibular EA................. 112

3.4.3 Os diretores/coordenadores/orientadores das escolas investigadas ................................................................ 113

3.4.3.1 A diretora do colégio público rural................. 113

3.4.3.2 O diretor do colégio público urbano............... 113

3.4.3.3 A orientadora do Colégio DP .......................... 114

3.4.3.4 O diretor do Colégio DB ................................. 114

3.4.3.5 A coordenadora do curso KN......................... 114

3.4.3.6 O coordenador do curso EA .......................... 115

3.4.4 Os elaboradores dos materiais didáticos..................... 115

3.4.4.1 O autor do livro didático usado na escola pública rural................................................. 115

3.4.4.2 O autor do livro didático usado na escola pública urbana ............................................ 116

3.4.4.3 O autor da apostila usada no Colégio DP ....... 116

3.4.4.4 O autor da apostila usada no Colégio DB....... 117 
3.4.4.5 O autor da apostila usada no curso KN ......... 118

3.4.4.6 O autor da apostila usada no curso EA ......... 118

3.4.3.7 A técnico-pedagoga de língua inglesa da Secretaria Estadual de Educação do Paraná .. 119

3.4.5 Os elaboradores da prova de língua inglesa do vestibular da UFPR.

4. Análise dos dados e discussão dos resultados - Parte I

125

4.1 Os documentos 126

4.1.1 Documentos oficiais 126

4.1.2 Análise das provas de inglês do vestibular da UFPR.... 133

4.1.3 Os planos de aulas dos professores de cada escola...... 158

4.1.4 manual do candidato do vestibular da UFPR.............. 160

4.2 Percepção dos elaboradores do exame.............................. 161

4.3 Percepções da coordenadora de língua inglesa da Secretaria Estadual de Educação. 165

4.3.1 O vestibular e a escola pública 165

4.3.2 O vestibular da UFPR. 173

5. Análise dos dados e discussão dos resultados - Parte II

5.1 A escola pública rural.

5.1.1 O diretor do Colégio EFA

5.1.2 As percepções do professor da Escola EFA.

5.1.3 As aulas do professor da Escola EFA

5.1.4 O livro da Escola EFA e as percepções de seu autor ....

5.1.5 Os alunos da Escola EFA

5.2 Escola pública urbana

5.2.1 O diretor da Escola LC 194

5.2.2 As percepções do professor da Escola LC 198

5.2.3 As aulas da professora da Escola LC.... 202

5.2.4 O livro do Colégio LC e as percepções de seu autor ..... 203

5.2.5 Os alunos da Escola LC.

5.3 Escola particular - o Colégio DB 207

5.3.1 O diretor do Colégio DB 208

5.3.2 As percepções do professor do Colégio DB. 216

5.3.3 As aulas do professor do Colégio DB 
5.3.4 A apostila e as percepções de seu elaborador

5.3.5 Os alunos do Colégio DB....

5.4 Escola particular - o Colégio DP

5.4.1 As orientadoras do Colégio DP ................................. 235

5.4.2 As percepções do professor do Colégio DP ................ 240

5.4.3 As aulas do professor do Colégio DP.......................... 246

5.4.4 A apostila do Colégio DP e as percepções de seu elaborador

5.4.5 As percepções dos alunos do Colégio DP ................... 250

5.5 Curso pré-vestibular para afrodescendentes....................... 254

5.5.1 As percepções da diretora do curso pré-vestibular KN.... 254

5.5.2 As percepções do professor do curso pré-vestibular KN .. 256

5.5.3 As aulas do professor do curso KN............................ 260

5.5.4 A apostila do curso pré-vestibular KN e as percepções de seu elaborador

5.5.5 As percepções dos alunos do curso pré-vestibular KN ... 265

5.6 Curso pré-vestibular para baixa renda................................ 269

5.6.1 O diretor do curso pré-vestibular EA........................ 269

5.6.2 As percepções do professor do curso pré-vestibular EA .. 272

5.6.3 As aulas do professor do curso EA.......................... 279

5.6.4 A apostila do curso pré-vestibular EA e as percepções de seu elaborador ................................................ 280

5.6.5 Os alunos do curso pré-vestibular EA...................... 283

6. Conclusões....................................................................... 297

6.1 Resumo das conclusões .................................................. 297

6.2 Contribuições .............................................................. 302

6.3 Limitações................................................................ 304

Posfácio.

A.1 Questionário I - Questionário para os alunos das escolas observadas

A.2 Questionário II - Questionário para os diretores e/ou coordenadores das escolas

A.3 Questionário III - Questionário para elaboradores da prova de língua inglesa do vestibular da UFPR

A.4 Questionário IV - Questionário para autores de materiais didáticos .. 317 
Apêndice B - Roteiro para entrevista

B.1 Roteiro para entrevista com professores das escolas observadas .... 321

B.2 Roteiro para entrevista II com diretores/coordenadores das escolas....

B.3 Roteiro para entrevista III com autoridade da Secretaria da Educação do Estado do Paraná .....

\section{Apêndice C - Exemplo do exame do IELTS}

C.1 Exemplo de um teste comunicativo baseado em tarefas - IELTS International English Language Testing System

Anexo A - Provas de língua inglesa do vestibular da UFPR.

A.1 Exemplos da prova de inglês do vestibular da UFPR de 1976 e 1977...

A.2 Exemplos da prova de inglês do vestibular da UFPR de 1988

A.3 Prova de inglês do vestibular da UFPR de 2000

A.4 Prova de inglês do vestibular da UFPR de 2001

A.5 Prova de inglês do vestibular da UFPR de 2002

A.6 Prova de inglês do vestibular da UFPR de 2003

A.7 Prova de inglês do vestibular da UFPR de 2004 362

A.8 Prova de inglês do vestibular da UFPR de 2005 364

A.9 Prova de inglês do vestibular da UFPR de 2006 368

Anexo B - Exemplo do exame Celpe-Bras

B.1 Exemplo de tarefa que integra leitura e produção escrita do manual do exame Celpe-Bras

B.2 Exemplo de tarefa que integra leitura e produção escrita do manual do exame Celpe-Bras

Anexo C - Exemplos da apostila utilizada no Colégio DB

C.1 Exemplos de explicação e exercício de gramática.

C.2 Exemplos de exercício de tradução.

C.3 Exemplos de questões de itens isolados de vestibulares.

C.4 Ensino de leitura - inglês instrumental 381

C.5 Ensino de leitura - texto e exercícios 382

C.6 Ensino de vocabulário. 383

Anexo D - Exemplos da apostila utilizada no Colégio DP 
D.2 Exemplos de exercício de interpretação, vocabulário e gramática.....388

D.3 Avaliação da disciplina de inglês do $3^{\circ}$ bimestre 391

Anexo E - Exemplos da apostila e exercícios avulsos utilizados no curso pré-vestibular KN 393

E.1 Exercício avulso de gramática e vocabulário 393

E.2 Exercício da apostila de vocabulário 394

E.3 Exercício de interpretação de texto, vocabulário e gramática 396

E.4 Simulado do curso KN 399

E.5 Exercício de leitura extra 400

Anexo F - Exemplos da apostila utilizada no curso pré-vestibular E A. 401 F.1 Exercícios de interpretação de textos de vestibulares anteriores ... 401

F.2 Exercícios de gramática. 403

Anexo G - Exemplos do material utilizado na Escola EFA .................. 405

G.1 Exercícios de interpretação de texto e vocabulário 405

G.2 Exercícios de leitura 407

G.3 Avaliação do bimestre 409

G.4 Plano de aula da Escola EAF - 2003 411

Anexo H - Exemplos do livro e avaliação da Escola LC 413

H.1 Explicação e exercícios de gramática 413

H.2 Avaliação do bimestre 415

H.3 Plano de aula - Escola LC - 2003. 417

H.4 Plano de aula da Escola LC (digitado) 418

Anexo I - Carta do aluno Allan Santos Torelli 419

Referências 
